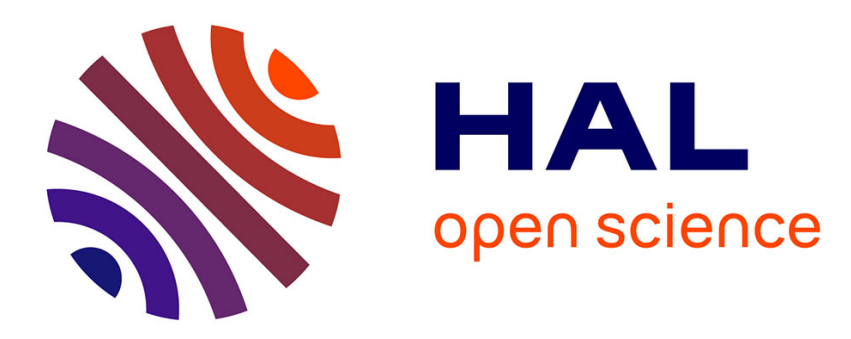

\title{
Le dépérissement du Chêne pédonculé en forêt communale d'Amance (Aube)
}

\author{
Alain Macaire
}

\section{To cite this version:}

Alain Macaire. Le dépérissement du Chêne pédonculé en forêt communale d'Amance (Aube). Revue forestière française, 1984, 36 (3), pp.201-205. 10.4267/2042/21725 . hal-03423612

\section{HAL Id: hal-03423612 \\ https://hal.science/hal-03423612}

Submitted on 10 Nov 2021

HAL is a multi-disciplinary open access archive for the deposit and dissemination of scientific research documents, whether they are published or not. The documents may come from teaching and research institutions in France or abroad, or from public or private research centers.
L'archive ouverte pluridisciplinaire HAL, est destinée au dépôt et à la diffusion de documents scientifiques de niveau recherche, publiés ou non, émanant des établissements d'enseignement et de recherche français ou étrangers, des laboratoires publics ou privés. 


\section{biologie \\ et forêt}

\section{LE DÉPÉRISSEMENT DU CHÊNE PÉDONCULÉ EN FORÊT COMMUNALE D'AMANCE (AUBE)}

\section{A. MACAIRE}

Le dépérissement du Chêne s'est manifesté çà-et-là à l'état diffus dans certaines forêts du département de l'Aube à partir de 1979 ; seule la forêt communale d'Amance a été fortement touchée.

Cette forêt, d'une surface de 338 hectares, fait partie du massif de la Forêt d'Orient - 16000 hectares - située en Champagne Humide à environ $30 \mathrm{~km}$ à l'est de Troyes.

Les Forêts de Champagne Humide reposent sur les argiles sableuses du Crétacé inférieur qui sont par place recouvertes par des limons quaternaires d'origine éolienne. Les sols sont de types variés mais toujours hydromorphes, la présence et l'épaisseur de limon déterminant leur degré d'hydromorphie.

Ces sols, d'une grande fertilité, permettent la production d'un chêne de très haute qualité. Des forêts, d'un grand renom, parsèment de l'Argonne à la Bourgogne cet étage du Crétacé : forêts domaniales de Lisle (Meuse), de Trois Fontaines (Marne), du Der (Haute-Marne), du Temple (Aube) et de Pontigny (Yonne).

\section{LA FORÊT COMMUNALE D'AMANCE}

La forêt communale d'Amance, aménagée en conversion en 1980, présente deux types de peuplements d'origine bien distincte:

- un taillis-sous-futaie enrichi sur 223 hectares (canton des Usages) provenant du cantonnement de droit d'usage de l'actuelle forêt domaniale du Temple; 
- des futaies peu denses plantées entre 1840 et 1860 sur d'anciennes pâtures communales abandonnées, sur 115 hectares (canton des Pâtures). Les archives du Centre indiquent que ces plantations ont été réalisées à partir de plants prélevés en forêt d'Amance à raison de 10000 plants/ha : chêne ( 5000 à 7500 plants/ha) et bouleau ( 5000 a 2500 plants/ha).

Comme dans toute la Champagne Humide, le Chêne pédonculé constitue en forêt communale d'Amance l'essentiel de la futaie.

\section{LE DÉPÉRISSEMENT DU CHÊNE EN FORÊT COMMUNALE D'AMANCE}

\section{Description des symptómes}

Le houppier s'éclaircit par mort et chute des rameaux à partir de l'extrémité des branches; en fin d'évolution, il ne reste plus que les charpentières dont l'ècorce est en voie de décollement. Un arbre en début d'évolution peut présenter des branches à différents stades de dépérissement.

Lorsque le dépérissement a lieu par bouquet, les premières branches dépérissantes "regardent " le plus souvent vers un arbre mort ou fortement dépérissant.

Le dépérissement ne s'accompagne jamais de descente de cime. Les Chẻnes les plus anciennement touchés présentent souvent des palmettes d'armillaire (Armillaria mellea) à plus de $2 \mathrm{~m}$ du sol.

Des fentes longitudinales de l'écorce accompagnées d'ècoulements noirâtres ont èté observées sur quelques sujets ainsi que des taches brunes sur l'écorce; ces symptômes pourraient être liés à la présence d'armillaire subcorticale.

Ces observations faites en 1980 ont constaté un dépérissement dont le début semble remonter à 1977. D'après les renseignements recueillis auprès du chef de Secteur et du chef de Triage, on peut décrire a posteriori l'évolution:

- en juillet 1977, après une forte attaque de chenilles défoliatrices, quelques chênes ont eu un feuillage très "clair" (peu de feuilles, feuilles décolorées et petites);

- en 1978, le dépérissement était plus accentué pour quelques chênes et se présentait déjà en bouquets ;

- en 1979, l'évolution s'est poursuivie, le feuillage des chênes atteints était très jauni en pleine saison de végétation et quelques arbres ètaient déjà secs;

- en 1980, l'amplification du phẻnomène a donné l'alerte.

L'évolution du dépérissement semble donc très rapide, en l'espace de 2-3 ans, les arbres atteints sont morts ou très déperissants.

\section{Répartition du dépérissement}

Les chênes atteints se situent dans toutes les classes de diamètre, d'áge et de dominance.

Diamètre 20-25: 209 tiges; Diamètre 30-45: 439 tiges; Diamètre 50 et $+: 216$ tiges.

Les arbres dépérissants se présentent:

- soit par bouquets allant jusqu'à une dizaine de sujets à différents stades d'évolution mélangés avec des arbres apparemment sains;

- soit par petits groupes de 3-4 chênes;

- soit par arbres isolés. 


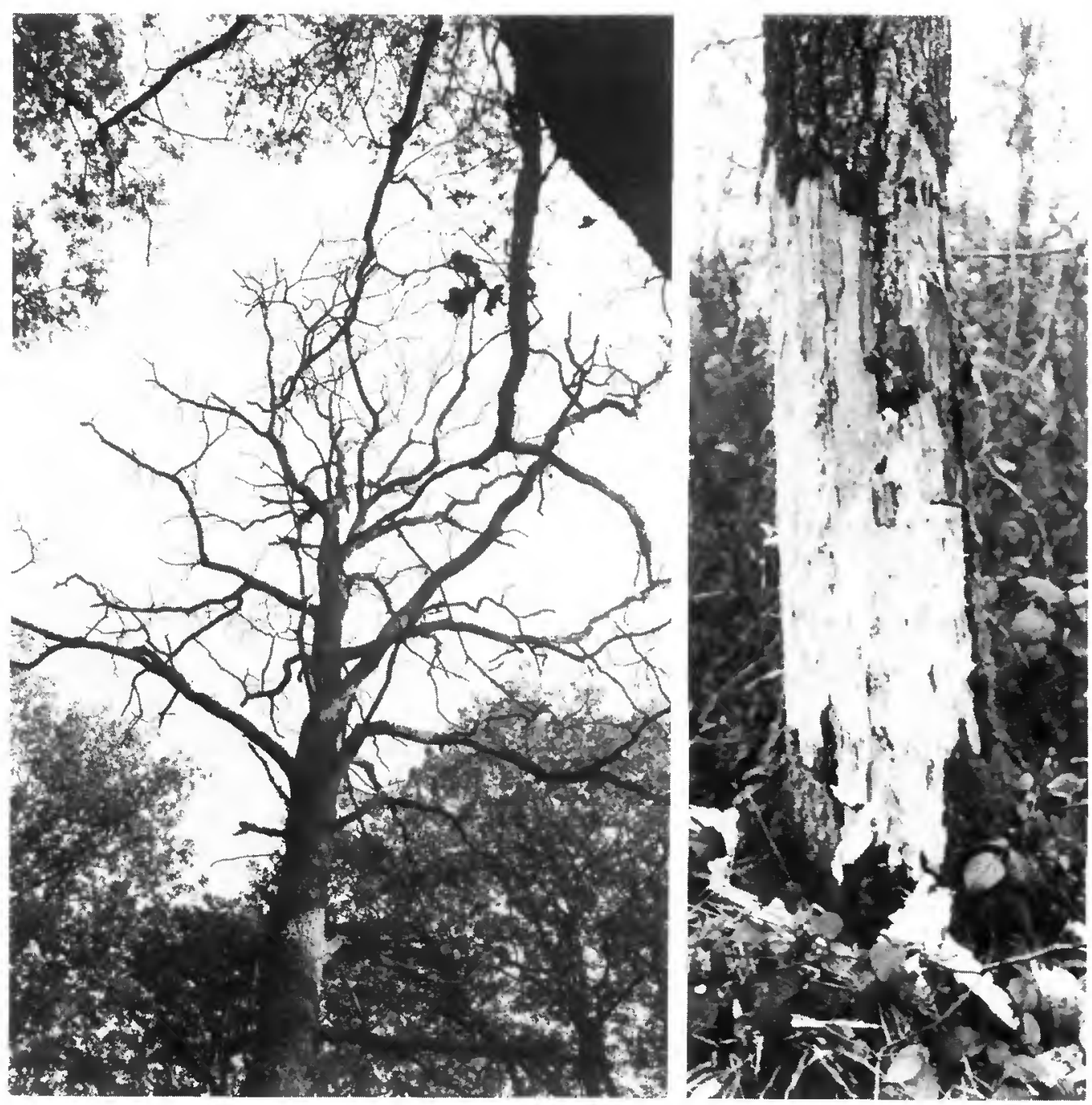

A gauche, Chêne mort entouré de sujets bien feuillés mais dont quelques branches présentent des signes de dépérissement.

A droite, palmettes d'Armillaire sur un Chêne écorcé manueillement.

Forêt communale d'Amance.

Photos A. MACAIRE

- Localisation des arbres dépérissants

La localisation du dépérissement semble sous la dépendance de deux facteurs:

- un facteur "peuplement"; toutes les parcelles plantées du canton des Pâtures ont été touchées par le dépérissement, $9 \mathrm{~m}^{3} /$ ha (volume grume) y ont été récoltés, représentant environ $8 \%$ du volume grume sur pied;

- un facteur pédologique; de fortes concentrations de chênes dépérissants se rencontrent sur les pseudogleys (parfois podzoliques) caractérisés par l'abondance de la molinie. La parcelie la plus atteinte, située dans le canton des Usages, a perdu $26 \%$ du matériel sur pied.

Il faut également noter la présence d'arbres disséminés sur les limons les plus lessivès, situés le plus souvent dans le canton des Pâtures. 


\section{A. MACAIRE}

\section{Hypothèses sur les causes du dépérissement}

- Le dépérissement est apparu après les années de pluviométrie déficitaire qui se sont achevées en 1976.

L'hypothèse du déficit hydrique expliquerait la forte abondance d'arbres morts sur les pseudogleys.

Une étude pédologique de la forêt communale d'Amance (Ch. Winckler, 1981) a montré que les sols à pseudogley et molinie étaient alimentés par une nappe profonde.

Lors d'une sécheresse importante, ces sols ne sont plus alimentés par cette nappe profonde d'origine locale et deviennent plus secs que les autres en raison de leur texture plus grossière (sables ou limons grossiers).

Les chênes, à l'enracinement déjà superficiel, auraient donc souffert terriblement de la faible réserve hydrique de ces pseudogleys podzoliques en 1976.

Cependant, cette hypothèse hydrique ne semble pas expliquer la présence abondante d'arbres atteints sur les sols lessivés à pseudogleys profonds qui se situent dans la moitié sud du massif (canton des Pâtures), car ceux-ci par leur profondeur possèdent normalement une meilleure réserve en eau.

- L'armillaire, parasite de faiblesse, pourrait être la cause de la mortalité d'arbres affaiblis par la succession d'années défavorables (déficit d'alimentation en eau et attaques répétées de chenilles défoliatrices)

La biologie du champignon semble sous la dépendance de deux facteurs du milieu : le $\mathrm{pH}$ et les conditions d'asphyxie.

C'est ainsi que :

- L'optimum de croissance de l'armillaire, coïncidant avec sa plus grande virulence, semble se situer à un $\mathrm{pH}$ relativement bas $(\mathrm{pH} \mathrm{4,2}$ en culture in vitro). Bien que le comportement in vitro et in situ du parasite puisse être différent, cette tendance pourrait expliquer la forte proportion de bois dépérissants sur les limons lessivés et les pseudogleys podzoliques.

- Les conditions d'asphyxie racinaire jouent un rôle important dans la virulence du parasite et sa croissance.

Les deux hypothèses suivantes peuvent ainsi être formulées:

- Les chênes affaiblis par les années de sécheresse n'auraient pu résister à la virulence de l'armillaire lorsque les conditions d'asphyxie racinaire sont redevenues "normales" dans les pseudogleys après l'èté 1976.

- C'est à la suite de la grande sécheresse de 1976 que les chênes parasitès meurent, car le système racinaire en partie détruit par le champignon ne permet pas de subvenir aux besoins hydriques de l'arbre.

\section{ÉVOLUTION DU DÉPÉRISSEMENT DEPUIS 1980}

L'évolution du dépérissement depuis 1980 est très diverse selon les situations :

- certains arbres continuent de depérir, avec évolution fatale de la maladie sur les pseudogleys podzoliques et dans les parcelles plantées. L'armillaire a été observé sur les arbres morts ou dépérissants, sous forme de palmette ou de rhizomorphe, dans neuf cas sur dix; 
- des arbres dépérissants en 1980 se sont rétablis sur les sols les moins hydromorphes ou sont dans un état stationnaire sur les sols les plus hydromorphes.

Des carottes de bois, prélevées à la tarière de Pressler en novembre 1983, ont montrè :

- une diminution très forte des accroissements annuels en 1976, 1977 et 1978 dans tous les cas ;

- une augmentation sensible des accroissements à partir de 1980 pour les sujets qui se sont rétablis ;

- le maintien d'accroissement réduit pour les arbres ayant continué de dépérir et pour ceux situés sur les sols à molinie.

\section{CONCLUSIONS}

Le déficit hydrique des années de sécheresse semble la cause du dépérissement du Chêne pédonculé, celui-ci a étè particulièrement abondant dans deux situations caractéristiques:

- sur des pseudogleys (podzoliques) à molinie ;

- dans des peuplements issus de plantations, car outre le canton des Pâtures d'Amance, les futaies plantées de deux autres forêts communales (Lignières et Marolles-sous-Lignières) ont été touchées, mais d'une façon moindre, par le dépérissement du Chêne.

La sécheresse de 1976 aurait donc éliminé les chênes pédonculés qui se sont trouvés dans des conditions d'alimentation en eau déficitaire pour des raisons pédologiques ou peut-être physiologiques (enracinement insuffisant de certaines futaies issues de plantation?).

Quelle que soit la cause exacte du dépérissement du Chêne, lié cependant à l'alimentation en eau de l'arbre - donc à son système racinaire - le forestier sylviculteur se doit de favoriser par des interventions économiquement supportables et au moment de l'installation d'un nouveau peuplement (régènération naturelle ou plantation), l'enracinement du chêne afin de diminuer, dans le peuplement adulte, les risques causés par les accidents climatiques.

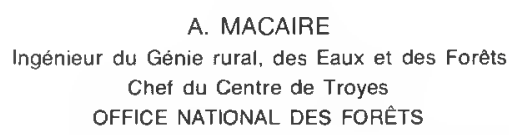

\section{BIBLIOGRAPHIE}

BECKER (M.), LEVY (G.). - Le dèpèrissement du Chêne en forêt de Tronçais. Les causes ècologiques. Annales des Sciences forestières, vol. $39, \mathrm{n}^{\circ} 4,1982$, pp. 439-444.

BECKER (M.). - Liaisons stations-production, dans une forêt sur sols hydromorphes. - Revue forestière française, $\mathrm{n}^{\circ} 4,1972$, pp. 269-287.

LANIER (L.). - Mycologie et Pathologie Forestière. Tome II. Paris : Masson, 1976, pp. 130-143.

MACAIRE (A.). - Le dèpèrissement du Chêne en forêt communale d'Amance. - Annexes de l'amènagement. O.N.F. 1980.

WINCKLER (Ch.). - Approche pédo-ècologique du Chêne en forêt communale d'Amance (Aube). Mèmoire D.A.A. Institut National Agronomique, 1981. 